\title{
Individual differences in syntactic priming in language acquisition
}

\author{
EVAN KIDD \\ La Trobe University and University of Manchester
}

Received: September 7, 2009 Accepted for publication: May 2, 2010

\author{
ADDRESS FOR CORRESPONDENCE \\ Evan Kidd, School of Psychological Sciences, University of Manchester, Oxford Road, Manchester \\ M13 9PL, UK. E-mail: e.kidd@latrobe.edu.au
}

\begin{abstract}
Although the syntactic priming methodology is a promising tool for language acquisition researchers, using the technique with children raises issues that are not problematic in adult research. The current paper reports on an individual differences study that addressed some of these outstanding issues. (a) Does priming purely reflect syntactic knowledge, or are other processes involved? (b) How can we explain individual differences, which are the norm rather than the exception? (c) Do priming effects in developmental populations reflect the same mechanisms thought to be responsible for priming in adults? One hundred twenty-two $(N=122)$ children aged 4 years, 5 months $(4 ; 5)-6 ; 11($ mean $=5 ; 7)$ completed a syntactic priming task that aimed to prime the English passive construction, in addition to standardized tests of vocabulary, grammar, and nonverbal intelligence. The results confirmed the widely held assumption that syntactic priming reflects the presence of syntactic knowledge, but not in every instance. However, they also suggested that nonlinguistic processes contribute significantly to priming. Priming was in no way related to age. Finally, the children's linguistic knowledge and nonverbal ability determined the manner in which they were primed. The results provide a clearer picture of what it means to be primed in acquisition.
\end{abstract}

Syntactic priming (or persistence) is the tendency for speakers to repeat a grammatical structure they have previously heard or said (Bock, 1986; Pickering \& Branigan, 1999). In adults, priming is taken as evidence that participants are processing the underlying abstract structure of language (e.g., Bock, 1986); in children, it is taken as evidence that they possess abstract knowledge of structure (e.g., Bencini \& Valian, 2008; Huttenlocher, Vasilyeva, \& Shimpi, 2004; Savage, Lieven, Theakston, \& Tomasello, 2003, 2006). Priming as a method in cognitive psychology is used to investigate the nature of mental representation. Therefore, syntactic priming provides a laboratory-based tool that enables researchers to investigate the nature of participants' linguistic knowledge and their sensitivity to variation in linguistic form in the input. For these reasons priming is a very promising tool for the study of language acquisition, where there is a significant debate about the representation of linguistic form and the role of input frequency as a source of information to the child language learner.

(C) Cambridge University Press 2011 0142-7164/11 \$15.00 
Kidd: Individual differences in syntactic priming in language acquisition

Despite the promise of the priming technique to language acquisition researchers, some of the central assumptions of priming have not been scrutinized, and some existing results need further corroboration. The current paper addressed three questions. First, does syntactic priming solely reflect the presence of syntactic knowledge, or are other processes involved? Second, what are the sources of individual differences in syntactic priming? Third, to what extent can priming effects in children be attributed to the same mechanisms invoked to explain priming effects in adults?

\section{PRIMING IN ACQUISITION}

In developmental research the priming paradigm has been employed to investigate the abstractness of children's syntactic representations. Motivated by the idea that children who possess abstract knowledge will be primed, the technique has been used to address a current debate in the literature that concerns the nature of children's early grammar. That is, do children have early abstract knowledge of grammar ("early syntax"; see Bencini \& Valian, 2008; Gentner, Fisher, \& Eisengart, 2006), or is language acquisition a more gradual process, particularly for lower frequency structures (e.g., Tomasello, 2003)? We concentrate here on production priming of the English passive construction, because this has been the greatest focus of priming research in acquisition, including the current study.

Savage et al. (2003) published the first paper that investigated syntactic priming in children. They attempted to prime 3-, 4-, and 6-year-old English-speaking children to use the get-passive (e.g., the window got smashed by the ball). They showed that (a) 3- and 4-year-old children were only primed in a condition where there was lexical overlap between prime and target (e.g., it got smashed by it primed it got pushed by it), and (b) 6-year-old children were primed when there was lexical and no lexical overlap. They concluded that only 6-year-old children have truly abstract knowledge of the (get-) passive, and that 3- and 4-year-olds only have partially abstract knowledge. A subsequent study that investigated the lasting effects of priming in 4-year-old children observed abstract priming in this age group (Savage et al., 2006). Furthermore, the priming effect persevered up to 1 month following the observation of the initial priming effect, but only when the primes to which children were exposed varied in lexical content. Therefore, it appears that some 4-year-olds have abstract knowledge of the get-passive construction.

This result is supported by other results in the literature. Huttenlocher, Vasilyeva, and Shimpi (2004) reported that 4- to 5-year-olds (mean age $=\sim 4$ years, 6 months [4;6]) were primed to use the passive and the dative constructions (e.g., Giuseppe gave the book to Charmaine), suggesting that 4-year-olds do have abstract knowledge of the passive (see also Messenger, Branigan, McLean, \& Sorace, 2008). Shimpi, Gámez, Huttenlocher, and Vasilyeva (2007) also observed priming in 4-year-olds, and reduced priming in 3-year-olds, leading them to suggest that 3year-old children also have abstract knowledge of the passive. On face value, this suggestion has some empirical support. Bencini and Valian (2008) reported a significant priming effect in young English-speaking 3-year-olds, who were primed to produce the passive. They consequently concluded that "three-year-olds can 
access two-level representations in which the concepts 'agent' and 'patient' exist separately from the grammatical relations 'subject' and 'object'" (p. 110).

The progression of the research suggests that priming effects are being observed in younger and younger children. The conclusion that is generally drawn is that when a priming effect is observed, it is an unambiguous demonstration of abstract syntactic knowledge in children of the age at which the effect was observed. A closer inspection across the developmental studies suggests that this conclusion may be too simplistic, because there appear to be large individual differences in children's performance within and between age levels. For instance, depending on the coding scheme used, between $40 \%$ and $80 \%$ of Bencini and Valian's (2008) 3 -year-olds produced passives sentences following passive primes, suggesting considerable individual differences. This is further suggested by large confidence intervals around the mean. In other words, even though $20 \%$ to $60 \%$ of their participants were not primed, they suggest that 3 -year-old children still possess abstract knowledge of the passive. This is not because of the young age of the children, because Messenger et al. (2008) have reported similarly variable performance in 4-year-olds. ${ }^{1}$

Individual differences in performance are suggestive of more subtle developmental processes than simply the presence or absence of knowledge (Bates, Dale, \& Thal, 1995). Shimpi et al. (2007) observed developmental differences in priming, whereby 4-year-old children were more easily primed than 3-year-olds, which they explained by suggesting that young children possess abstract syntactic knowledge, but are not adept at accessing this knowledge for speech (p. 1343). This explains away developmental differences by appealing to performance limitations. Although common in acquisition research (for a discussion, see McKee \& McDaniel, 2004), such interpretations dismiss age effects as truly developmental phenomena. As such, the current discourse on priming takes for granted that a significant priming effect reflects the presence of syntactic knowledge in the age group as a whole, but dismisses the absence of priming as experimental noise.

Missing from this chain of reasoning is the demonstration that priming reflects syntactic knowledge. One can imagine two possible scenarios. First, if the lack of priming is due to experimental noise and not the absence of knowledge, then children in an age group that are primed should not differ in linguistic knowledge from children in same age group who are not primed. In this case, a lack of priming is simply error attributable to extraneous variables (e.g., attention). Second, if priming is due to the presence of knowledge, then children who are primed should be more linguistically sophisticated than children who are not primed. The difference between these two positions is not trivial. The first suggests that children acquire knowledge of abstract linguistic structure early in acquisition and that this is connected to age in a nontrivial way; the second suggests that the process of abstraction is a developmental process and that age is only a poor proxy for the combined forces of learning rate and experience with language. The current paper tested these two scenarios.

Another question that has not been raised in the priming literature is the extent to which priming reflects nonverbal learning processes. Priming, at least in production, is the process of aligning structure and meaning across different situations. For example, when asked to describe a picture of an arrow hitting a target after 
hearing the window was broken by the ball, children who are primed may choose to describe the picture by producing the target was shot by the arrow. To do so requires that the child detect semantic similarities across both situations (i.e., both scenes depict transitive acts) and map structure onto that meaning. As such, this requires that children engage in something like pattern finding or analogical mapping (Gentner \& Namy, 2006; Genter \& Markman, 1997; Tomasello, 2003). The current study tested whether children's nonverbal pattern finding ability contributed to the likelihood that they would be primed.

Finally, the current study tested the extent to which priming in children reflects implicit learning. There have been some suggestions in the literature that priming reflects implicit learning of structure, most notably shown by Savage et al. (2006), who showed that priming can last up to 1 month following initial testing (see also Experiment 3 in Huttenlocher et al., 2004). The prevailing wisdom in the adult literature is that priming is largely an implicit phenomenon (e.g., Chang, Dell, \& Bock, 2006), as demonstrated the adults being primed over periods of up to 10 intervening filler trials. Explicit processes, however, have been invoked to explain cases of priming where there is lexical overlap between prime and target. For instance, when Ludo gave Laura a cake primes Judith gave Nancy a book, where prime and target have the same verb. Such cases of priming are generally shortlived, with any priming effect decaying almost immediately (Branigan, Pickering, \& Cleland, 2000). The data suggest that priming in acquisition reflects implicit learning is encouraging, insofar as there is potential comparability between the adult and child data. However, there are crucial differences in the experimental methods in the child and adult studies. First, the child studies have not generally tested enough items to test for learning effects throughout the experiment. Second, at least in the case of Savage et al. (2003, 2006), fairly unusual items were used. They tested children only on transitive scenes where one inanimate entity acted upon another (e.g., the arrow got shot by the target). This highly atypical situation might have cued the children in their study to be more likely to use a passive in subsequent testing sessions. The current study rectified these potential methodological shortcomings by testing children on a large number of items that are more typical of children's everyday experience.

To summarize, the current literature on syntactic priming in children suggests that there are large individual differences in children's propensity to be primed, and it is unclear whether priming effects reflect implicit learning processes. One possible explanation for the individual variability is that it simply reflects experimental noise (e.g., Shimpi et al., 2007). An alternative explanation is that it reflects children's linguistic knowledge and therefore that the use of chronological age as a determinant of developmental achievement is less than optimal. Because age only acts as a proxy variable in development, we favor the latter hypothesis: that priming reflects differences in knowledge and abilities that vary within as well as between age groups. The current study aimed to test these two competing explanations. One hundred twenty-two children $(N=122)$ aged $4 ; 5$ to $6 ; 11$ completed a syntactic priming task that aimed to prime the English passive construction. They also completed standardized tests of grammar and vocabulary, and a test of nonverbal ability. It was hypothesized that those children who are primed would score higher on tests of linguistic and nonlinguistic knowledge than children who 
are not primed. Second, it was hypothesized that the magnitude of individual children's priming effect will be predicted by their linguistic knowledge. Finally, following Huttenlocher et al. (2004) and Savage et al. (2006), it was hypothesized that those children who were primed during their first testing session would be more likely to be primed 1 week later.

\section{METHOD}

\section{Participants}

One hundred twenty-two $(N=122)$ children aged 4;5-6;11 $(M=5 ; 7, S D=$ 8.4) were recruited from primary schools in a large metropolitan city in northern England. Five children were removed from the final sample: four because their nonverbal ability was less than 2 standard deviations below the mean for their age group, and one because the child's grammatical knowledge was 2 standard deviations below the mean for their age group. The age parameters remained the same for the final sample. The children in the final sample all spoke English as their first language and possessed no language or cognitive impairments.

The children were slightly older than the children from the past research that has shown priming effects, for a number of reasons. First, we used the full BEpassive as primes, which is acquired later than the get-passive (e.g., see Budwig, 1990; Marchman, Bates, Burkhardt, \& Good, 1991). Second, as argued above, the past studies that have reported priming effects in 3- and 4-year-olds do not provide unequivocal evidence for the presence of robust abstract knowledge of the passive construction because large group variability has been reported in each study. Therefore, we recruited slightly older children in larger proportions with the aim of recruiting a sample that possessed a distribution of linguistic and cognitive skills within the normal range, thereby maximising the power of our individual differences analyses. ${ }^{2}$

\section{Materials and procedure}

The children completed a battery of linguistic and nonlinguistic tasks. They completed a test of syntactic priming, standardized tests of vocabulary and grammar, and a test of nonverbal ability. The children were tested individually in a quiet room at their school. The presentation of the tasks was counterbalanced to average potential differential carry over effects. Each child was tested over two testing sessions that were approximately 1 week apart ( \pm 2 days). We describe each task below.

Test of vocabulary. Children's vocabulary was measured using the British Picture Vocabulary Scale-Second Edition (BPVS; Dunn, Dunn, Whetton, \& Burley, 1997). The BPVS is a published standardized test that measures receptive vocabulary in children. In this test children are orally presented with a word. Children are asked to identify the picture that matches the word from an array of four. A receptive measure of vocabulary was selected on the grounds that expressive measures are considered to tap into working memory processes in addition to 
lexical knowledge (Brownell, 2000). The test has a standardized mean of 100, with a standard deviation of 15. Children's raw scores on this test were used in the analyses.

Test of Receptive Grammar (TROG). The TROG (2nd ed.; Bishop, 2003) is a standardized test of children's comprehension of grammatical contrasts. In it children are shown an array of four pictures and are asked to match a sentence read to them by the experimenter to the corresponding picture. A range of grammatical constructions are tested, including simple transitive sentences, passives, and relative clauses. The test terminates when participants fail on five consecutive blocks of testing, which each comprise four sentences testing a particular feature of grammar. Therefore, not all children are tested on every item; however, because the items become progressively more difficult, a higher score is indicative of more sophisticated grammatical knowledge. The test was selected because, as with the BPVS, it is a receptive measure, and therefore minimizes working memory load. The test has a standardized mean of 100 and a standard deviation of 15 . Children's raw scores on this test were used in the analyses.

Test of nonverbal reasoning. The Raven's Coloured Progressive Matrices (RCPM; Raven, 2004) was used to assess nonverbal reasoning. In this test children are presented with a series of stimulus pictures of abstract patterns. In each picture there is a piece missing; the child's task is to choose the missing piece that matches the pattern in the stimulus picture from an array of six possible alternatives. The RCPM was chosen because it is a measure of pattern-finding ability. The test has a standardized mean of 100 and a standard deviation of 15 . The children's raw scores were used in the analyses.

Syntactic priming task. The syntactic priming task was designed to prime passive sentences. Forty-two pictures depicting transitive scenes that could be described using either an active or a passive construction were used. Twelve of these were prime pictures (see Appendix B), and 30 were test pictures that were rotated throughout the different testing phases of the task. The pictures all depicted scenes that contained different actions, such that the children were less likely to use a verb from a prime sentence in their descriptions of the pictures.

Because this was an individual differences study, the syntactic priming task was within-subjects (e.g., Kaschak, 2007; Kaschak, Loney, \& Borreggine, 2006; Nitschke, Kidd, \& Serratrice, 2010). This deviates slightly from previous studies investigating priming in children, but was necessary because of the focus on individual differences in priming. The task consisted of four blocks: (a) baseline, (b) test, (c) posttest, and (d) posttest (Week 2). During the baseline block the children were simply asked to describe a picture without guidance from the experimenter. Children described six pictures in this block. The next block was the test block, in which children were primed. In this block the children were told that this time the experimenter would describe one picture, and that they would have to describe the following picture. The children were asked to repeat the experimenter's prime sentence. The experimenter always described the primes using a full BE passive containing a by-phrase; for example, the guitar was played by the man. The 
passive construction was chosen because (a) it has been the most successfully primed construction in acquisition research, (b) it is very low in frequency in spoken language in its full $\mathrm{BE}$ form and seems to only be mastered after formal reading instruction $(<1 \%$ in either its full or truncated form in spoken English; Bencini \& Valian, 2008). This maximized the chances of observing a priming effect, because children are unlikely to produce passives spontaneously. All prime sentences contained action verbs. The prime sentences are listed in the Appendix $\mathrm{B}$; their presentation was pseudorandomized across the 10 lists. Following the test block, the children described a further six pictures without being primed. This was the posttest block. Finally, during their second testing session approximately 1 week after the first session, the children described a further six pictures without priming. This final session was included in an attempt to replicate long-term priming effects observed by Savage et al. (2006). There was never overlapping content shared by consecutive pictures, reducing the possibility that children's priming effect could be attributable to lexical overlap.

The pictures that the children described were fully rotated through the four blocks of testing using 10 experimental lists. Each picture occurred in the test block in 4 out the 10 lists, with roughly an equal number of children being tested on each list. Rotating the test pictures through the 10 lists meant that each test picture had a baseline score, a test score, a posttest score, and posttest (Week 2) score. Previous priming studies that have tested children have generally included a lower number of items (e.g., Bencini \& Valian, 2008; Huttenlocher et al., 2004; Savage et al., 2003, 2006; Shimpi et al., 2007; cf. Messenger et al., 2008), and so have either not reported items analyses or have done so with a small number of items. In the present study we were able to test the robustness of the priming effect by including a large number of items.

\section{Scoring}

The test sessions were audio recorded and later transcribed. Following Bencini and Valian (2008), multiple priming measures are reported. Whereas they reported three measures (lax, strict, and adult) we report only two (lax and strict), because Bencini and Valian reported no substantial differences between the strict and adult coding schemes. The lax and strict coding schemes are described below.

Lax coding scheme. The children's descriptions of the target pictures were coded as (a) active, (b) passive, or (c) other. Active sentences required an overt subject, a transitive verb optionally preceded by a form of be or have, and an optional direct object. Passives required the patient in the subject position, the main verb optionally preceded by be or get, and optionally followed by the agent or instrument of the action within an adjunct headed by the prepositions by or with. That is, both truncated (e.g., The window was broken) and full passives (e.g., The window was broken by the boy) were included in the lax coding. The priming effect was calculated by dividing the total number of passive responses by the number of trials in each phase; that is, the priming effect was an index of the proportion of passive constructions produced as a function of the total number of opportunities the children were given in each phase of the experiment. 
Kidd: Individual differences in syntactic priming in language acquisition

Table 1. Descriptive statistics for measures of vocabulary (BPVS), grammar (TROG), and nonverbal intelligence (RCPM)

\begin{tabular}{lrrccr}
\hline \hline & Mean & $S D$ & Range & Skewness & Kurtosis \\
\hline BPVS & 103.27 & 14.47 & $70-137$ & .573 & -.228 \\
TROG & 100.76 & 16.58 & $72-145$ & .924 & .781 \\
RCPM & 93.03 & 14.91 & $70-130$ & .924 & .625 \\
\hline \hline
\end{tabular}

Note: BPVS, British Picture Vocabulary Scale; TROG, Test of Receptive Grammar; RCPM, Raven's Coloured Progressive Matrices.

Strict coding scheme. The strict coding scheme was the same as the lax scheme, except that to be coded as a passive the children's utterances needed to contain a postverbal adjunct that encoded the agent or instrument of the action headed by the prepositions by or with. That is, only full passives were counted on the strict coding scheme.

\section{RESULTS}

This section is organized as follows. The descriptive statistics for each test are reported, followed by a general consideration of the priming effect. The relationship between the priming effect and the language and nonverbal tests are then explored. Specifically, we tested whether the children who were primed during the test and posttest phases differed on the measures of language and nonverbal ability.

\section{Descriptive statistics}

The descriptive statistics for the test of vocabulary, grammar, and nonverbal intelligence are presented in Table 1.

The means for the BPVS and TROG reflected the standardized population mean (i.e., 100), whereas the mean for the RCPM was slightly lower although still in the normal range. The children's scores on the BPVS were normally distributed; their scores on the TROG and the RCPM were positively skewed; significant Kolmolgorov-Smirnov tests indicated that these two distributions deviated from the normal distribution (TROG: $Z=1.64, p=.009$; RCPM: $Z=1.63, p=.01$ ). The TROG and RCPM data were transformed using a $\log _{10}(x)$ transformation, after which the scores for both variables followed a normal distribution (TROG: $Z=.871, p=.434$; RCPM: $Z=1.24, p=.09$ ). Subsequent analyses using these variables used the transformed data.

\section{Priming effect}

Each response was coded as (a) passive, (b) active, (c) intransitive, or (d) other. Across the four blocks of the task, the children produced passive descriptions (both full and truncated) $8 \%$ of the time, active descriptions $65 \%$ of the time, intransitive descriptions $17.7 \%$ of the time, and "other" descriptions $9.2 \%$ of the 
Applied Psycholinguistics 33:2

Kidd: Individual differences in syntactic priming in language acquisition

Table 2. Means (standard deviations) for each experimental block of the syntactic priming task

\begin{tabular}{llccl}
\hline \hline & Baseline & Test & Posttest & \multicolumn{1}{c}{ Week 2 } \\
\hline Lax & $0.017(0.06)$ & $0.15(0.16)$ & $0.11(0.17)$ & $0.019(0.06)$ \\
Strict & $0.01(0.04)$ & $0.10(0.14)$ & $0.07(0.15)$ & $0.01(0.05)$ \\
\hline \hline
\end{tabular}

time. Other descriptions mainly consisted of fragments (e.g., running, A frog; $7.4 \%)$, but also included datives $(0.9 \%)$, presentational constructions $(0.6 \%)$, and infinitival complements $(0.3 \%)$. The dependent measure for the priming task was the number of passive constructions used as a proportion of the number of items in each experimental block (baseline, test, posttest, and posttest Week 2). The means and standard deviations for each experimental block for both the lax and strict scoring methods are shown in Table 2.

Table 2 shows that the children produced very few spontaneous passives during the baseline phase of the experiment $(\leq 2 \%)$. However, following priming in the test block the children's use of passives increased substantially (10\%-15\%), although the high standard deviations suggest that there was substantial variability. The children's use of the passive persisted in the posttest block (7\%-11\%), and fell off sharply 1 week later, where they used the passive in proportions similar to the baseline phase.

The data were analyzed using a four-way repeated-measures analysis of variance using testing block as the independent variable and the proportion of passive constructions as the dependent measure. The proportion data were initially transformed using an $2 \times \operatorname{arcsine}(\sqrt{ } x)$ transformation (Howell, 1992). For the lax coding scheme, the main effect of block was significant by participants $\left(F_{1}\right)$ and items $\left(F_{2}\right), F_{1}(3,114)=56.3, p<.001$, partial $\eta^{2}=0.327 ; F_{2}(3,27)=50.78$, $p<.001$, partial $\eta^{2}=0.636, \min ^{\prime} F(3,82)=26.7, p<.001$. Post hoc Bonferroni comparisons showed that the children produced significantly more passives in the test and posttest blocks than in the baseline and posttest Week 2 blocks (all $p s<.001$ ), and more in the test block than in the postest block (by participants $p=.014$; by items $p=.052$ ). In addition, there was no reliable difference between the children's use of the passive during the baseline and posttest Week 2 blocks.

The results did not change for the strict coding scheme. The main effect of block was significant by participants and items, $F_{1}(3,114)=46.24, p<.001$, partial $\eta^{2}=0.285 ; F_{2}(3,27)=39.71, p<.001$, partial $\eta^{2}=0.578, \min ^{\prime} F(3,79)=21.36$, $p<.001$. Post hoc Bonferroni comparisons showed that the children produced significantly more passives in the test and posttest blocks than in the baseline and posttest Week 2 blocks (all $p s<.01$ ), and more passives in the test block than in the posttest block, which was significant by participants $(p<.001)$ and once again marginal by items $(p=.092)$. In addition, there was no reliable difference between the children's use of the passive during the baseline and posttest Week 2 blocks. 
Kidd: Individual differences in syntactic priming in language acquisition

The reliable statistical difference between the baseline and the test and posttest blocks establishes the presence of a syntactic priming effect, a minimal requirement for the present study. We now explore the nature of the priming effect, first by investigating the priming effect across time, and then by exploring the relationship between the priming effect and the other dependent measures.

The time course of the priming effect. Analyzing the children's use of the passive construction across the priming task has the potential to shed light on the role of implicit and explicit processes in syntactic priming. If priming reflects explicit processes and by implication transient activation then there should not be an increase in the use of passives across the course of the test phase. That is, children should be primed equally at different time points in the task. In contrast, if syntactic priming reflects implicit learning then there should be a buildup over time, such that priming should increase at the initial stage of the experiment but attenuate at the end. This prediction derives from Chang et al.'s (2006) categorization of syntactic priming as an implicit process that is driven by error-based learning, which argues that the magnitude of the priming reflects the difference between the observation of the scene (i.e., transitive) and the linguistic form of the prime (i.e., transitive scene $\rightarrow$ passive). Because this difference will initially be large, the implicit learning approach predicts a rise in the magnitude of priming that will attenuate once the difference between unexpected mapping of the passive form onto a transitive scene lessens (i.e., through repeated exposure). As such, the implicit learning approach predicts that the landscape of the priming effect will resemble a traditional learning curve (Ebbinghaus, 1885/1913).

Figure $1 \mathrm{a}$ and $\mathrm{b}$ shows the means (and standard errors) across the experimental blocks, which have been divided into segments that contain three items each, thus yielding two data points for the baseline block, four data points for the test block, and two each for posttest, and posttest Week 2 blocks.

Figure $1 \mathrm{a}$ and $\mathrm{b}$ shows that the priming effect builds up following the first three items and peaks at the third three. The effect decreases across the posttest period, and returns to baseline at Week 2.

To investigate the development of the priming effect over the test block, the four segments were entered into repeated-measures analysis of variance, which revealed a significant effect for both the lax and strict coding schemes, lax: $F(3,114)=5.58, p=.001$, partial $\eta^{2}=0.046$; strict: $F(3,114)=6.69, p<$ .001 , partial $\eta^{2}=0.055$. Post hoc Bonferroni comparisons showed that, for both coding schemes, the children produced significantly more passives in the second, third, and fourth test segment than in the first segment (all $p \mathrm{~s}<.03$ for both coding schemes), with no other significant effects. Furthermore, trend analyses conducted on the data revealed significant linear and quadratic trends, lax: linear $F(1,116)=$ $6.99, p=.009$, partial $\eta^{2}=0.057$, quadratic $F(1,116)=8.07, p=.005$, partial $\eta^{2}=0.065$; strict: linear $F(1,116)=9.78, p=.002$, partial $\eta^{2}=0.078$, quadratic $F(1,116)=9.4, p=.003$, partial $\eta^{2}=0.075$. These final results suggest that the development of the priming effect is nonlinear.

With respect to the posttest block, the children produced significantly more passive sentences in the first three trials than on the last three trials for the both coding schemes, lax: $t(117)=2.26, p=.026, d=0.23$, two-tailed; strict: $t(117)=$ $2.07, p=.041, d=0.17$, two tailed. 


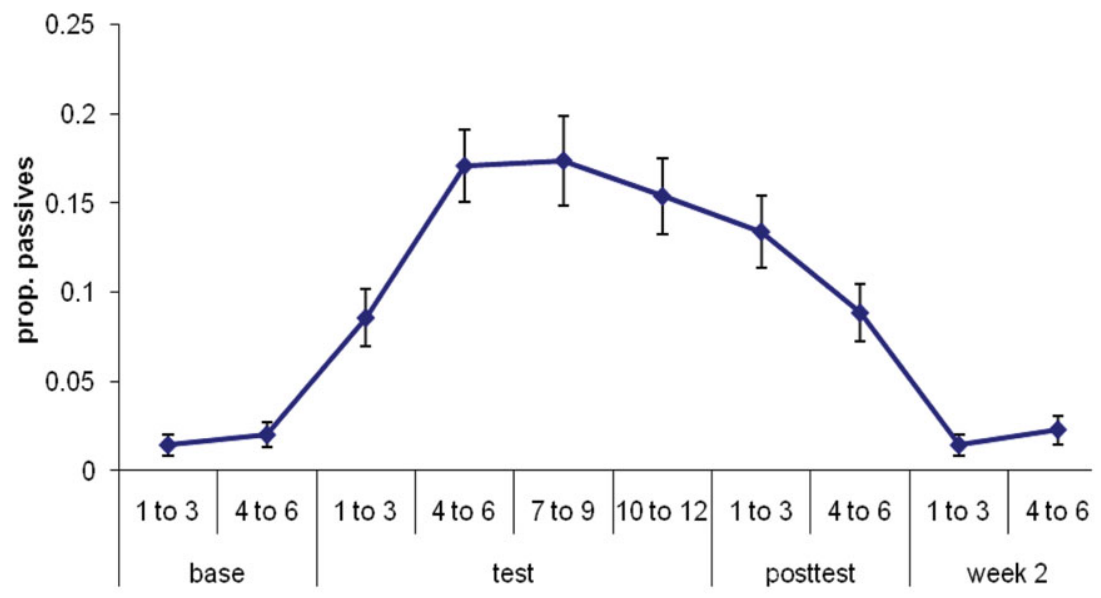

(a)

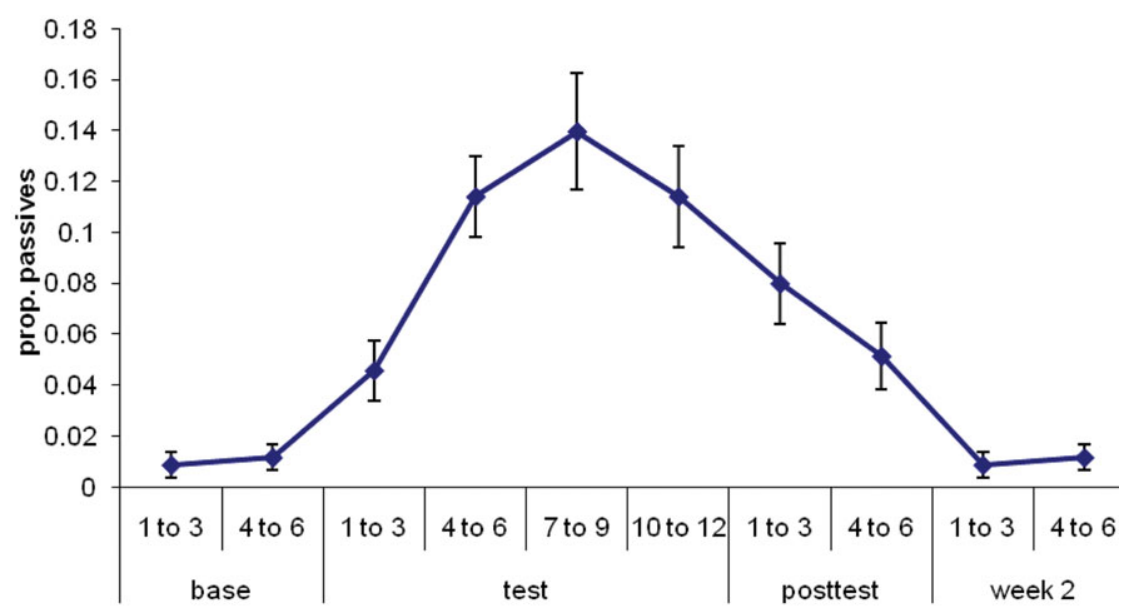

(b)

Figure 1. Means (standard errors) of priming effect across time for (a) the lax coding scheme and (b) the strict coding scheme.

The results of the analysis of the development of priming effect over time suggest that the effect builds up, supporting the implicit learning account, but that it decays during the posttest period, when no more primes were administered. This decay suggests that, following suggestions made by Pickering and Ferreira (2008) in their review of the adult data, both transient activation and implicit learning contribute to syntactic priming.

Individual differences in priming. There were large individual differences in the data. On the lax coding scheme, $70.9 \%(n=83)$ of the children were primed 
Kidd: Individual differences in syntactic priming in language acquisition

Table 3. Comparison of children who were and who were not primed during the test block

\begin{tabular}{clrrrrr}
\hline \hline & Group & Mean & \multicolumn{1}{c}{$S D$} & $t$ & $p$ & $d^{a}$ \\
\hline Lax & & & & & & \\
Age & Primed & 67.02 & 8.03 & 0.908 & .366 & 0.17 \\
& Not primed & 65.47 & 9.27 & & & \\
BPVS & Primed & 59.51 & 14.42 & 0.426 & .671 & 0.08 \\
& Not primed & 58.21 & 16.27 & & & \\
TROG & Primed & 9.10 & 3.46 & 1.41 & .163 & 0.26 \\
& Not primed & 8.26 & 3.62 & & & \\
RCPM & Primed & 16.40 & 4.75 & 1.39 & .168 & 0.26 \\
& Not primed & 15.09 & 3.90 & & & \\
Strict & & & & & & \\
Age & Primed & 67.58 & 8.33 & 1.51 & .133 & 0.28 \\
& Not primed & 65.22 & 8.37 & & & \\
BPVS & Primed & 61.10 & 14.30 & 1.67 & .097 & 0.31 \\
& Not primed & 56.48 & 15.46 & & & \\
TROG & Primed & 9.49 & 3.53 & 2.60 & $.011^{*}$ & 0.48 \\
& Not primed & 8.00 & 3.33 & & & \\
RCPM & Primed & 17.07 & 4.91 & 3.03 & $.003 *$ & 0.57 \\
& Not primed & 14.60 & 3.58 & & & \\
\hline \hline
\end{tabular}

${ }^{a}$ Cohen $d$.

${ }^{*} p<.0125$ (two tailed).

in the test block (i.e., they produced at least one passive), and $43.6 \%(n=51)$ produced at least one passive in the posttest block. On the strict coding scheme, $57.3 \%(n=67)$ of children were primed in the test block, and only $25.6 \%(n=30)$ produced at least one passive in the posttest block. We next present two different analyses of these data. First, we investigated whether the children who were primed differed from the children who were not primed on any of the associated measures collected. This analysis was repeated for the posttest block. Second, we then investigated whether the magnitude of the priming effect in the subset of children who were primed can be predicted by their age, their existing linguistic knowledge (vocabulary and grammar), and their nonverbal ability.

The first question we asked concerns whether or not there are any differences between children who were primed and children who were not primed. These two groups were compared on (a) age (in months), (b) vocabulary (BPVS), (c) grammatical knowledge (TROG), and (d) nonverbal ability (RCPM).

Table 3 provides the means and standard deviations for the children who were and who were not primed during the test block on the four dependent measures using the lax and strict coding schemes, along with the results from independent $t$ tests that compared the two groups on each measure (with Bonferroni correction for each coding scheme: $\alpha=0.05 / 4=0.0125$ ).

Table 3 shows that the children who were primed and those who were not primed only differed in their grammatical knowledge and nonverbal intelligence when the 
Kidd: Individual differences in syntactic priming in language acquisition

Table 4. Results from the logistic regression on the data from the strict coding scheme

\begin{tabular}{lclllll}
\hline \hline & $B$ & $S E(B)$ & Wald & $d f$ & $p$ & $\operatorname{Exp}(B)$ \\
\hline Months & 0.022 & 0.026 & 0.723 & 1 & .395 & 1.022 \\
BPVS & -0.014 & 0.018 & 0.597 & 1 & .440 & 0.986 \\
TROG & 2.42 & 1.63 & 2.18 & 1 & .139 & 11.19 \\
RCPM & 5.18 & 2.36 & 4.82 & 1 & $.028^{*}$ & 177.13 \\
Constant & -8.74 & 2.82 & 9.63 & 1 & $.002^{*}$ & 0.000 \\
\hline \hline
\end{tabular}

Note: BPVS, British Picture Vocabulary Scale; TROG, Test of Receptive Grammar; RCPM, Raven's Coloured Progressive Matrices.

$* p<.05$.

strict coding scheme was considered. In both cases, the children who were primed had significantly higher scores, suggesting that they had more advanced syntactic knowledge and nonverbal skills. In order to tease apart these differences, all four variables were entered into a binary logistic regression, this time as independent variables. The dependent measure was whether or not the children were primed. Table 4 presents the results.

Table 4 shows that the regression model was significant $\left(\chi^{2}=14.33, d f=\right.$ $\left.4, p=.006, R^{2}=.156^{3}\right)$. However, only nonverbal ability, as measured by the RCPM, predicted the tendency for children to be primed, after controlling for the contribution of the other variables. This suggests that tendency to be primed in general is primarily determined by children's nonverbal ability.

We also compared the children who produced passives in the posttest block to those who did not produce any passives. Unlike during the test block, none of the comparisons were significant.

Predicting the magnitude of the priming effect. We next investigated whether the magnitude of the priming effect in the children who were primed can be predicted by their linguistic knowledge and/or nonverbal ability. These analyses were motivated by the logic that, if the priming method taps into children's syntactic representations, then those children who are more linguistically adept should be primed more than children whose linguistic knowledge is less developed. In the context of the present study, we therefore expected the number of passives that the children produced to be significantly correlated with their linguistic knowledge. Therefore, this set of analyses only includes children who were primed.

Table 5 shows the simple correlations between the children's priming score, their age (in months), and their scores on the BPVS (vocabulary), TROG (grammar), and the RCPM (nonverbal intelligence) for the lax coding scheme. Table 6 shows the same results using the strict coding scheme.

Table 5 shows that, on the lax coding scheme, vocabulary and grammatical knowledge were significantly positively correlated with the magnitude of the priming effect. Table 6 reports the same result for the strict coding scheme. Two multiple linear regressions were run to tease apart the contributions of the variables 
Kidd: Individual differences in syntactic priming in language acquisition

Table 5. Simple correlations between the magnitude of the priming effect, age (months), and scores on the BPVS, TROG, and RCPM (lax coding scheme)

\begin{tabular}{lllll}
\hline \hline & Months & BPVS & TROG & RCPM \\
\hline Test & .022 & $.320 * *$ & $.236^{*}$ & .048 \\
Months & & .124 & .178 & $.237 *$ \\
BPVS & & & $.612^{* * *}$ & $.505 * * *$ \\
TROG & & & & $.497 * * *$ \\
\hline
\end{tabular}

Note: BPVS, British Picture Vocabulary Scale; TROG, Test of Receptive Grammar; RCPM, Raven's Coloured Progressive Matrices.

$* p<.05 . * * p<.01 . * * * p<.001$.

Table 6. Simple correlations between the magnitude of the priming effect, age (months), and scores on the BPVS, TROG, and RCPM (strict coding scheme)

\begin{tabular}{lllll}
\hline \hline & Months & BPVS & TROG & RCPM \\
\hline Test & -.095 & $.355^{* *}$ & $.352 * *$ & .001 \\
Months & & .121 & .127 & .178 \\
BPVS & & & $.562 * * *$ & $.509 * * *$ \\
TROG & & & & $.459 * * *$ \\
\hline
\end{tabular}

Note: BPVS, British Picture Vocabulary Scale; TROG, Test of Receptive Grammar; RCPM, Raven's Coloured Progressive Matrices.

$* * p<.01 . * * * p<.001$.

of age, vocabulary, and grammatical knowledge, and nonverbal ability to the magnitude of the priming. The results are presented in Table 7.

Both regression models were significant. The model in Table 7 shows that, for the lax coding scheme, only vocabulary knowledge significantly contributed to the magnitude of the priming effect. For the strict coding scheme, both vocabulary and grammatical knowledge significantly contributed independent amounts of variance. In the model for the strict coding scheme nonverbal ability (RCPM) also contributes to the magnitude of the priming effect, but the negative beta coefficient suggests that it is acting as a suppressor variable. From Tables 5 and 6 we can see that the BPVS, the TROG, and RCPM are intercorrelated. Although they are not correlated enough to be problematic to the solution, ${ }^{4}$ the moderate correlation between the BPVS, TROG, and the RCPM suggests that they overlap in the concepts they measure. Because the RCPM is nonverbal, it is reasonable to suggest that the BPVS and TROG both measure linguistic knowledge and nonverbal ability. The negative beta weight for the RCPM therefore reflects the 
Kidd: Individual differences in syntactic priming in language acquisition

Table 7. Multiple regression summary for predictors of the magnitude of the priming effect for both coding schemes

\begin{tabular}{lccccccc}
\hline \hline & \multicolumn{2}{c}{ Lax Coding Scheme } & & \multicolumn{3}{c}{ Strict Coding Scheme } \\
\cline { 2 - 3 } \cline { 7 - 8 } & Multiple $R\left(R^{2}\right)$ & $\beta$ & $p$ & & Multiple $R\left(R^{2}\right)$ & $\beta$ & $p$ \\
\hline \multirow{3}{*}{ Months } & $.358^{*}(.128)$ & & & & $.493 * *(.244)$ & & \\
BPVS & & .002 & .983 & & -.123 & .293 \\
TROG & .340 & $.020^{*}$ & & .348 & $.021^{*}$ \\
RCPM & .120 & .406 & & .307 & $.035^{*}$ \\
\hline \hline
\end{tabular}

Note: BPVS, British Picture Vocabulary Scale; TROG, Test of Receptive Grammar; RCPM, Raven's Coloured Progressive Matrices. $* p<.05$.

Table 8. Means and standard deviations for age (months), vocabulary, grammar, and nonverbal ability for each group based on passive type produced

\begin{tabular}{llrrr}
\hline \hline & & Mean & $S D$ & $N$ \\
\hline \multirow{2}{*}{ Age (months) } & Truncated only & 64.24 & 6.38 & 17 \\
& Mixed & 70.32 & 8.30 & 25 \\
& Full passive & 65.54 & 7.44 & 37 \\
BPVS & Truncated only & 52.47 & 12.97 & 17 \\
& Mixed & 59.92 & 16.42 & 25 \\
& Full passive & 62.05 & 12.25 & 37 \\
TROG & Truncated only & 7.29 & 2.61 & 17 \\
& Mixed & 9.00 & 2.75 & 25 \\
RCPM & Full passive & 9.97 & 4.01 & 37 \\
& Truncated only & 13.47 & 2.55 & 17 \\
& Mixed & 16.40 & 5.67 & 25 \\
& Full passive & 17.38 & 4.27 & 37 \\
\hline \hline
\end{tabular}

Note: BPVS, British Picture Vocabulary Scale; TROG, Test of Receptive Grammar; RCPM, Raven's Coloured Progressive Matrices.

removal of variance associated with nonverbal ability from the TROG and the BPVS.

Because vocabulary and grammar differentially predicted the magnitude of the priming effect for the different coding schemes, the final analysis investigated whether the children's use of truncated and full passives was associated with their vocabulary and grammatical knowledge, and their nonverbal ability. We divided the children who were primed into three groups: (a) those who produced truncated passives only, (b) those who produced both truncated and full passives (i.e., mixed), and (c) those who only produced full passives. The means and standard deviations for each group are presented in Table 8. 
These data were analyzed using a multivariate analysis of variance, with passive group as the independent measure and age and vocabulary, grammar, and nonverbal ability score entered as dependent measures. The multivariate term was significant, $F(8,148)=2.61, p=.011$, partial $\eta^{2}=0.124$. All between-participants effects were also significant except for the BPVS, which was marginal, months: $F(2,76)=$ 4.24, $p=.018$, partial $\eta^{2}=0.100$; TROG: $F(2,76)=3.66, p=.03$, partial $\eta^{2}=0.088$; RCPM: $F(2,76)=5.18, p=.008$, partial $\eta^{2}=0.12$; BPVS: $F(2$, $76)=2.83, p=.066$, partial $\eta^{2}=0.069$. Univariate comparisons showed that, for the TROG and RCPM, the full passives group scored significantly higher than the truncated passives only group, but that both groups did not differ significantly from the mixed group (all $p \mathrm{~s}<.03$ ). For the variable of age, the mixed group was significantly older than both the truncated passives only group $(p=.036)$ and the full passives only group $(p=.049)$.

\section{DISCUSSION}

The current research asked three questions about syntactic priming effects during first language acquisition. The first concerned the extent to which syntactic priming effects directly reflect linguistic knowledge and nonverbal ability. The second concerned the source of individual differences typically observed in syntactic priming studies conducted with children. The third concerned the role of implicit and explicit learning processes in syntactic priming in children. Each of these issues is considered below.

With respect to the first two questions, the results appear to be rather clear. Overall, we observed significant priming effects on both the lax and strict coding schemes. Because the children were primed in the absence of lexical overlap, this suggests that children aged (on average) 5.5 years possess abstract knowledge of the passive, both full and truncated. However, this conclusion must be qualified by a more detailed consideration of the patterns of individual differences in the results. Priming on the lax coding scheme was related to the children's linguistic knowledge, specifically, their vocabulary knowledge. Priming on the strict coding scheme was predicted by the children's nonverbal ability and their linguistic knowledge, in this case both their grammatical knowledge and their vocabulary. Such results are to be expected if we accept the argument that priming taps into linguistic knowledge. However, in no way was priming related to age, suggesting that interpretations of priming effects as reflecting knowledge states for given age groups are incorrect (e.g., Benicni \& Valian, 2008; Shimpi et al., 2007).

The children's nonverbal ability predicted their tendency to be primed to use full passives (i.e., the strict coding scheme). There are two potential explanations for this effect. The first is procedural and the second theoretical. The procedural explanation is that the effect reflects that priming requires the detection of structural and semantic similarities across prime and target items and that, because the RCMP is a measure of pattern finding, children who score higher on the test are more likely to identify this pattern. In a detailed examination of the adult version of the test, the Raven's Progressive Matrices, Carpenter, Just, and Shell (1990) showed that individuals who performed well on the test were primarily distinguished by (a) an ability to induce abstract relations between stimuli and (b) an ability to 
dynamically manage a large set of problem solving goals in working memory. It appears that those children with superior pattern finding ability were more likely to seize upon and use the syntactic pattern that was primed. Whether or not these children had productive knowledge of the full BE passive prior to the experiment is an open question. If they did not, the result would suggest that nonverbal ability aids in the explicit learning of syntactic structure, following the suggestion that there is a close coupling between language learning and nonverbal ability (Karmiloff-Smith, 2009). If they already possessed productive knowledge of the passive, then the results suggest that nonverbal ability predicts success on the task itself. This possibility feeds into the theoretical explanation of this effect. Pickering and Garrod (2004) have argued that priming reflects alignment between speakers. Thus, it is possible that those children who possess higher nonverbal abilities are simply more likely to align syntactically with their interlocutors. A third possibility is that both of these explanations account for the effect, but that each emphasizes a different aspect of the phenomenon: the first being strictly cognitive and the second a combination of cognitive and social. Future research is needed to decide between these possibilities.

The magnitude of the priming effect was predicted by children's vocabulary knowledge on the lax coding scheme, and by their vocabulary and grammatical knowledge on the strict coding scheme. This result is likely to reflect that, on the lax coding scheme, children were given credit for a truncated passive (e.g., The window was broken), whereas on the strict coding scheme only full passives were accepted (e.g., The window was broken by the boy). Furthermore, when the children were divided into groups according to the kinds of passives that they produced, those who produced only truncated passives had significantly lower grammatical knowledge and nonverbal ability than the children who produced full passives.

Although the current literature on priming in acquisition does not always distinguish between these two forms, past accounts on the acquisition of the passive have highlighted their different functions and their different developmental schedules (Budwig, 1990). For instance, Horgan (1978) showed that almost all young children's use of the passive to describe pictures were agentless passives that contained an inanimate surface subject (e.g., the lamp was broken). Similarly, Marchman et al. (1991) showed in an elicited production task that children only begin to produce full passives above chance at 8 years, and do not use the full BE passive at all until they are aged 7 years. Furthermore, comprehension studies have shown that children understand these forms before they understand full passives (Maratsos, Fox, Becker, \& Chalkley, 1985; Sudhalter \& Braine, 1985). The status of these truncated forms as true passives is unclear. Israel, Johnson, and Brooks (2000) argued that the adjectival stative passive is the source construction from which children learn full eventive passives and presented naturalistic data to support this hypothesis. Such a treatment is consistent with a learning account whereby children learn form-meaning pairings and gradually extend essentially lexically based passives to syntactically complex full passive forms (see also Abbot-Smith $\&$ Behrens, 2006). The results from the current data confirm the largely lexical status of truncated passives, because it was only children's vocabulary knowledge that predicted priming when truncated passives were included in the analyses. In 
contrast, that both grammatical and vocabulary knowledge predicted performance on full passives suggests that slightly different processes are involved, with full passives implicating grammatical knowledge to a greater extent.

Although we observed differences between the children who were primed and the children who were not primed during the test block, these differences disappeared in the posttest block. Overall, fewer children produced passives during the posttest period. This was because some children who were primed during the test phase did not produce any passives in the posttest block (44 in both lax and strict coding schemes), rather than the reverse being the case (12 lax, 7 strict). We argue that this result, combined with the children producing fewer passives in the posttest block than in the test block, suggests that priming in acquisition relies on continual reinforcement of the target structure. This could be due to children's developing verbal working memory, because children must have a working memory trace for a prime in order to use the same structure to describe the test picture. If children are still yet to have full functional use of the passive, they may instead prefer to use more fully entrenched structures such as the active in the absence of a strong memory trace for competing low-frequency structures such as the passive. Alternatively, it could be explained by children's developing executive function skills, whereby children may be unable to suppress the production of the well-learned active form.

The children in the current study also failed to exhibit priming 1 week after the initial priming task. This is inconsistent with results reported by Savage et al. (2006), who showed long-term priming both 1 week and 1 month after an initial priming session. There are two potential reasons for the differences between the studies. As argued in the introduction, the materials used by Savage et al. (2006) may have alerted the children to the aim of the experiment because they always involved two inanimate entities engaging in prototypically transitive actions, which generally require an animate agent (e.g., the target got shot by the arrow). Because they also only tested the children on the priming task, the children may have effectively seen the task as "the passive game." In contrast, the participants in the current study were tested on a wider array of items and on a number of different tests, and were therefore less likely to have been alerted to the aims of the task. ${ }^{5}$

Vasilyeva, Huttenlocher, and Waterfall (2006) have also reported long-term priming. Over a period of 2 weeks children (mean age $=4 ; 4$ ) were told 10 stories that either had a high proportion of passive or active sentences embedded in them (the "passive" stories had, on average 61\% passives). At the end of the week their production and comprehension of the passive was assessed: the group that heard the stories that contained a high proportion of passives performed better on both the comprehension and production task than did the children who heard a larger proportion of actives. This is a fairly unambiguous demonstration of long-term priming, and the results are instructive for several reasons. First, they suggest that long-term priming of a low-frequency structure such as the passive may require a large number of exemplars over a distributed time frame in order to observe any long-term representational changes (see also Ambridge, Theakston, Lieven, \& Tomasello, 2006). Second, they suggest that learning may be most optimal when children are presented target structures in meaningful contexts (i.e., within a story). These are potential reasons why the current study did not observe long-term 
priming a week after the first testing session. Quite simply, it could be that (a) children require many more than 12 tokens of a low-frequency structure in one session in order to change their long-term linguistic behavior (for corroborating evidence see Brooks \& Tomasello, 1999), and (b) they benefit more from materials that are embedded in more naturalistic contexts.

This discussion of learning brings us to the final aim of the present study: to investigate the extent to which syntactic priming reflects implicit and explicit learning processes. The children's production of passives accumulated across the test phase of the priming task, supporting the prediction that priming reflects implicit learning processes, as argued by Chang et al. (2006). According to Chang et al. (2006), priming is driven by error-based learning; the priming effect reflects the minimization of error between prediction and observation. Because adult participants do not seem to have insight into this process and because it persists across intervening filler trials (see Bock, Dell, Chang, \& Onishi, 2007; Bock \& Griffin, 2000), the process is argued to be largely implicit. This account of priming argues that priming reflects changes in the strength of association between form and meaning. If the data from the test phase reflect these changes, then why was there decreased use of the passive during the posttest phase and a return to baseline levels 1 week later? As argued above, it is likely that priming reflects processes other than just implicit learning, which contributed to the attenuation of the effect across time. Further teasing out these processes is a priority for future research.

One final issue to consider in studies of syntactic priming in children is whether the children come to the experiment with full knowledge of the structures they use, or whether they, in fact, learn throughout the experiment. This is an issue that requires careful experimentation, possibly with the use of novel structures. Children's ability to learn new structures has been well documented in studies using the weird word order methodology (e.g., Abbot-Smith, Lieven, \& Tomasello, 2001; Akhtar, 1999; Chang, Kobayashi, \& Amano, 2009), so it is possible that children are doing so with low-frequency structures such as the passive. The current data, however, do not bear on the issue, which awaits further research.

\section{APPENDIX A}

A significant priming effect does not require many exemplars of the target structure. For example, Huttenlocher et al. (2004) reported a "highly significant" (p. 186) priming effect for the passive after observing 22 passives from 15 children, an average of 1.47 passives per child. In fact, a priming effect can be significant with as few as 0.5 exemplars of the target structure per child. Consider the following mock experiment: 24 children participate in an experiment aimed at priming the passive. Half are allocated to a group that receives 10 passive primes, and the other half receive 10 active primes. If one child in the active group spontaneously uses one passive sentence (such an occurrence would follow the frequency of use in the ambient language, that is, $<1 \%$ ), then a significant priming effect would be observed if six children in the passive group produced one passive each, as shown in Table A.1.

In this instance, if, following Huttenlocher et al. (2004), we take the proportion of passives as the dependent measure, we see that the proportion of passives in the passive 
Kidd: Individual differences in syntactic priming in language acquisition

Table A.1. Mock priming experiment data

\begin{tabular}{cccc}
\hline \hline & \multicolumn{3}{c}{ Child Utterance Form } \\
\cline { 2 - 4 } Priming Condition & Active & Passive & Other \\
\hline Active & $107(89 \%)$ & $1(<1 \%)$ & $12(10 \%)$ \\
Passive & $100(83 \%)$ & $6(5 \%)$ & $14(12 \%)$ \\
Difference & $+7(+6 \%)$ & $+5(+4 \%)$ & \\
\hline \hline
\end{tabular}

condition is $5 \%$, whereas in the active condition it is $0.83 \%$, a difference that is significant $t(22)=2.24, p=.024, d=0.96$. The effect size $(d)$ here is "large" on Cohen's (1988) criteria; however, it is likely that most child language researchers would be sceptical that such effects constitute knowledge of the passive in the age group from which the children were drawn. The problem here is that the results tell us very little about the children who were primed other than that they produced one passive each. Note that it is not a given that the children knew the passive before the experiment, because even 2-year-olds can be primed to use weird word orders when they could never have heard them before (e.g., Abbot-Smith, Lieven, \& Tomasello, 2001; Akhtar, 1999; Mathews, Lieven Theakston, \& Tomasello, 2005, 2007). We clearly need to know more about what it means to be primed in acquisition.

\section{APPENDIX B: PRIME SENTENCES AND PICTURES}

1. The toys were carried by the wagon.

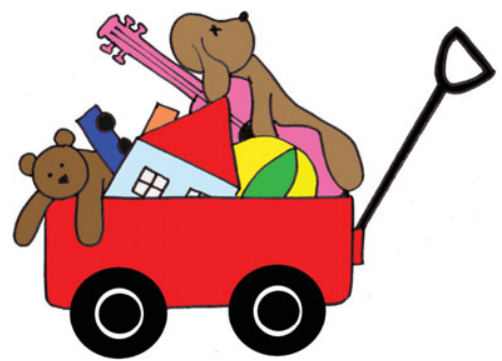

2. The food was cooked by the man.

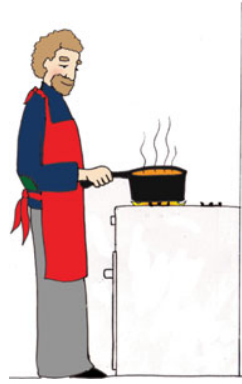


Applied Psycholinguistics 33:2

Kidd: Individual differences in syntactic priming in language acquisition

3. The target was shot by the arrow.

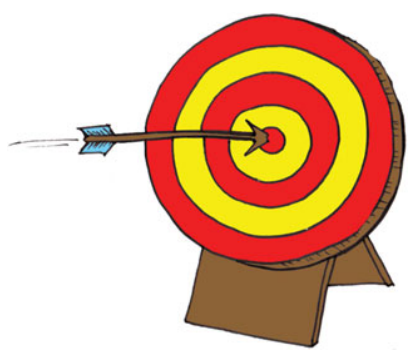

4. The feather was blown by the girl.

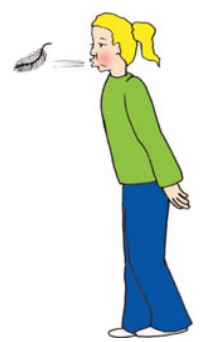

5. The biscuit was eaten by the girl.

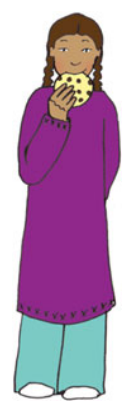

6 . The guitar was played by the man.

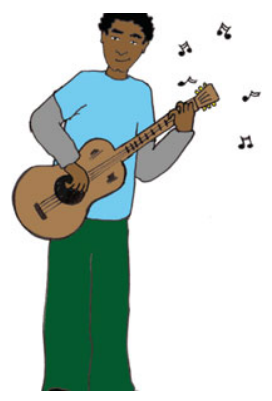


Applied Psycholinguistics 33:2

Kidd: Individual differences in syntactic priming in language acquisition

7. The door was opened by the boy.

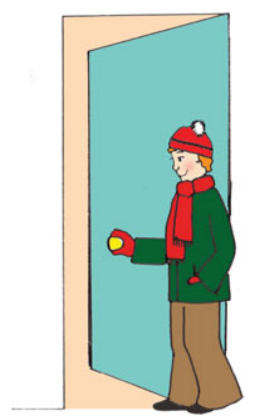

8. The treasure was buried by the pirate.

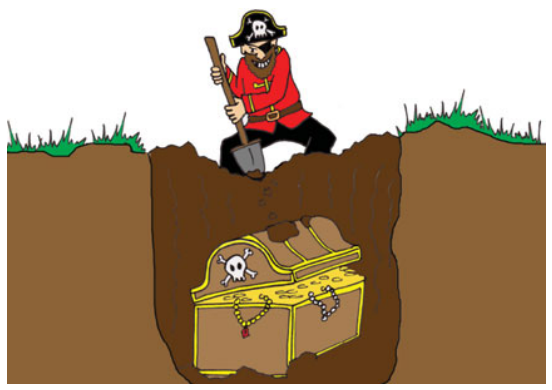

9. The flower was watered by the rain
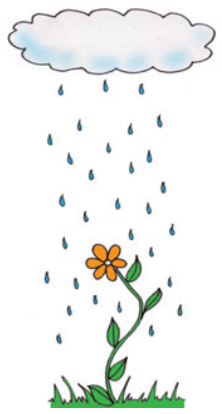

10. The cake was cut by the knife.

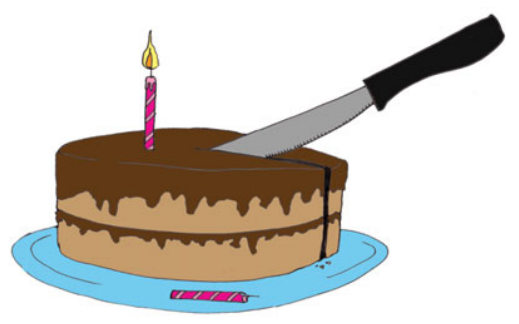


11. The window was broken by the ball.

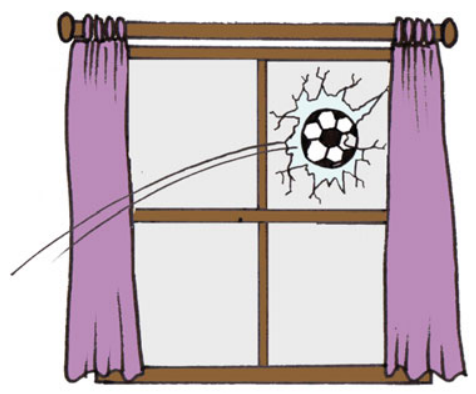

12. The fish was caught by the net.

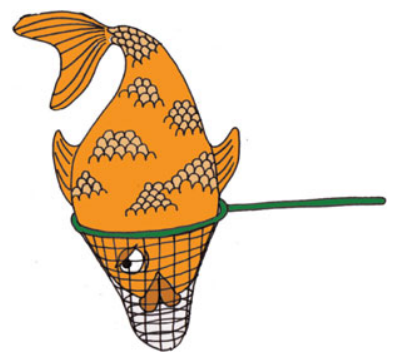

\section{ACKNOWLEDGMENTS}

This research was supported by the Nuffield Foundation (SGS/33866) and a Charles La Trobe Research Fellowship. Thanks to Rachael King for testing the children, Siu-Lin Rawlinson for drawing the pictures, and Franklin Chang and Ludovica Serratrice for helpful comments.

\section{NOTES}

1. Savage et al. (2003, 2006), Huttenlocher et al. (2004), and Shimpi et al. (2007) did not report any measures of variability. For a concrete example of how priming effects do not depend on whole group performance, see Appendix A.

2. Recruiting older children potentially stacks the odds against our hypothesis that priming effects should reflect the presence of linguistic knowledge. This is because if, following the logic of Shimpi et al. (2007), young children have knowledge of the passive but cannot access it, they should certainly all be able to do so some 1.5-2 years later.

3. $R^{2}=$ Nagelkerke $R^{2}$ statistic.

4. All tolerances $>0.5$ (where $<0.2$ suggests multicollinearity) and variance inflation factor statistics $<1.7$ (where variance inflation factor $>5$ indicates multicollinearity) were acceptable. 
Kidd: Individual differences in syntactic priming in language acquisition

5. Seven items in the current study had two inanimates, and 21 contained one animate (agent) and 1 inanimate (theme; e.g., the man kicked the ball). The remaining two contained 2 animates. When animacy was included as a variable in the priming analysis, items that contained 2 inanimates were significantly more likely to result in the use of a passive at every testing block than items that contained 1 animate and 1 inanimate (items with 2 animates were excluded). However, there was no interaction with animacy, suggesting that (a) transitive scenes with 2 inanimates are in general more likely to elicit the use of the passive, and (b) higher priming effects are to be expected when 2 inanimates are used.

\section{REFERENCES}

Abbot-Smith, K., \& Behrens, H. (2006). How known constructions influence the acquisition of other constructions: The German passive and future constructions. Cognitive Science, 30, 995 1026.

Abbot-Smith, K., Lieven, E., \& Tomasello, M. (2001). What pre-school children do and do not do with ungrammatical word orders. Cognitive Development, 16, 679-692.

Akhtar, N. (1999). Acquiring basic word order: Evidence for data-driven learning of syntactic structure. Journal of Child Language, 26, 339-356.

Ambridge, B., Theakston, A., Lieven, E., \& Tomasello, M. (2006). The distributed learning effect for children's acquisition of an abstract grammatical construction. Cognitive Development, 21, 174-193.

Bates, E., Dale, P. S., \& Thal, D. (1995). Individual differences and their implications for theories of language development. In P. Fletcher \& B. MacWhinney (Eds.), Handbook of child language (pp. 96-151). Oxford: Blackwell.

Bencini, G. M. L., \& Valian, V. V. (2008). Abstract sentence representations in 3-year-olds: Evidence from language production and comprehension. Journal of Memory and Language, 59, $97-$ 113.

Bishop, D. (2003). Test of Receptive Grammar (2nd ed.). Oxford: Harcourt Assessment.

Bock, J. K. (1986). Syntactic persistence in language production. Cognitive Psychology, 18, 355-387.

Bock, J. K., Dell, G. S., Chang, F., \& Onishi, K. H. (2007). Persistent structural priming from language comprehension to language production. Cognition, 105, 437-458.

Bock, J. K., \& Griffin, Z. M. (2000). The persistence of syntactic priming: Transient activation or implicit learning? Journal of Experimental Psychology: General, 129, 177-192.

Branigan, H. P., Pickering, M. J., \& Cleland, A. A. (2000). Syntactic priming in written production: Evidence for rapid decay. Psychonomic Bulletin \& Review, 6, 635-640.

Brooks, P., \& Tomasello, M. (1999). Young children learn to produce passive with nonce verbs. Developmental Psychology, 35, 29-44.

Brownell, R. (2000). Expressive One-Word Picture Vocabulary Test. Novato: Academic Therapy Publications.

Budwig, N. (1990). The linguistic marking of non-prototypical agency: An exploration into children's use of passives. Linguistics, 28, 1221-1252.

Carpenter, P. A., Just, M. A., \& Shell, P. (1990). What one intelligence test measures: A theoretical account of the processing in the Raven Progressive Matrices Test. Psychological Review, 97, 404-431.

Chang, F., Dell, G. S., \& Bock, J. K. (2006). Becoming syntactic. Psychological Review, 113, 234-272.

Chang, F., Kobayashi, T., \& Amano, S. (2009). Social factors in the acquisition of a new word order. First Language, 29, 427-445.

Cohen, J. (1988). Statistical power analysis for the behavioral sciences. Hillsdale, NJ: Erlbaum.

Cohen, M. J. (1997). Children's memory scales. San Antonio, TX: Psychological Corporation.

Dunn, L. M., Dunn, L. M., Whetton, C., \& Burley, J. (1997). The British Picture Vocabulary Scale. London: NFER-Nelson.

Ebbinghaus, H. (1885/1913). Memory: A contribution to experimental psychology. New York: Columbia University, Teachers College. 
Applied Psycholinguistics 33:2

Kidd: Individual differences in syntactic priming in language acquisition

Ferreira, V. S., \& Bock, J. K. (2006). The functions of syntactic priming. Language and Cognitive Processes, 21, 1011-1029.

Genter, D., \& Namy, L. L. (2006). Analogical processes in language learning. Current Directions in Psychological Science, 15, 297-301.

Gentner, D., \& Markman, A. B. (1997). Structure mapping in analogy and similarity. American Psychologist, 52, 45-46.

Gertner, Y., Fisher, C., \& Eisengart, J. (2006). Learning words and rules: Abstract knowledge of word order in early sentence comprehension. Psychological Science, 17, 684-691.

Horgan, D. (1978). The development of the full passive. Journal of Child Language, 5, 65-80.

Howell, D. C. (1992). Statistical method of psychology (3rd ed.). Belmont, CA: Duxbury Press.

Huttenlocher, J., Vasilyeva, M., Cymerman, E., \& Levine, S. (2002). Language input and child syntax. Cognitive Psychology, 45, 337-374.

Huttenlocher, J., Vasilyeva, M., \& Shimpi, P. (2004). Syntactic priming in young children. Journal of Memory and Language, 50, 182-195.

Israel, M., Johnson, C., \& Brooks, P. (2000). From states to events: The acquisition of English passive participles. Cognitive Linguistics, 11, 103-129.

Karmiloff-Smith, A. (2009). Nativism versus neurocontructivism: Rethinking the study of developmental disorders. Developmental Psychology, 45, 56-63.

Kaschak, M. P. (2007). Long-term structural priming affects subsequent patterns of language production. Memory \& Cognition, 35, 925-937.

Kaschak, M. P., Loney, R. A., \& Borreggine, K. L. (2006). Recent experience affects the strength of structural priming. Cognition, 99, B73-B82.

Maratsos, M. P., Fox, D. E. C., Becker, J. A., \& Chalkley, M. A. (1985). Semantic restrictions on children's passives. Cognition, 19, 167-191.

Marchman, V., Bates, E., Burkhardt, A., \& Good, A. (1991). Functional constraints on the acquisition of the passive: Toward a model of competence to perform. First Language, 11, 65-92.

Matthews, D., Lieven, E., Theakston, A., \& Tomasello, M. (2005). The role of frequency in the acquisition of English word order. Cognitive Development, 20, 121-126.

Matthews, D., Lieven, E., Theakston, A., \& Tomasello, M. (2007). French children's use and correction of weird word orders: A constructivist account. Journal of Child Language, 34, 381409.

McKee, C., \& McDaniel, D. (2004). Multiple influences on children's language performance. Journal of Child Language, 31, 489-492.

Messenger, K., Branigan, H., McLean, J., \& Sorace, A. (2008). English-speaking children's early passives: Evidence from syntactic priming. In H. Chan, H. Jacob, \& E. Kapia (Eds.), Proceedings of the 32nd annual Boston University conference on language development (pp. 275-286). Somerville, MA: Cascadilla Press.

Nitschke, S., Kidd, E., \& Serratrice, L. (2010). First language transfer and long-term structural priming in L1 and L2 comprehension. Language and Cognitive Processes, 25, 94-114.

Pickering, M. J., \& Branigan, H. P. (1998). Syntactic priming in language production. Trends in Cognitive Sciences, 3, 136-141.

Pickering, M. J., \& Branigan, H. P. (1999). The representation of verbs: Evidence from syntactic priming in language production. Journal of Memory and Language, 39, 633-651.

Pickering, M. J., \& Ferreira, V. S. (2008). Syntactic priming: A critical review. Psychological Bulletin, $134,427-459$.

Pickering, M. J., \& Garrod, S. (2004). Toward a mechanistic psychology of dialogue. Behavioral and Brain Sciences, 27, 169-225.

Raven, J. (2004). Coloured Progressive Matrices and Chrichton Vocabulary Scale. London: Pearson Assessment.

Raven, J. C., Court, J. H., \& Raven, J. (1987). A manual for Raven's Progressive Matrices and Vocabulary Tests. London: H. K. Lewis.

Savage, C., Lieven, E. V. M., Theakston, A. L., \& Tomasello, M. (2003). Testing the abstractness of children's linguistic representations: Lexical and structural priming of syntactic constructions in young children. Developmental Science, 6, 557-567.

Savage, C., Lieven, E. V. M., Theakston, A. L., \& Tomasello, M. (2006). Structural priming as implicit learning in language acquisition: The persistence of lexical and syntactic priming in 4-year-olds. Language Learning and Development, 2, 27-49. 
Kidd: Individual differences in syntactic priming in language acquisition

Shimpi, P. M., Gámez, P. B., Huttenlocher, J., \& Vasilyeva, M. (2007). Syntactic priming in 3and 4-year-old children: Evidence for abstract representations of transitive and dative forms. Developmental Psychology, 43, 1334-1346.

Sudhalter, V., \& Braine, M. (1985). How does comprehension of passives develop? A comparison of actional and experimental verbs. Journal of Child Language, 12, 455-470.

Tomasello, M. (2003). Constructing a language: A usage-based theory of language acquisition. Cambridge, MA: Harvard University Press.

Vasilyeva, M., Huttenlocher, J., \& Waterfall, H. (2006). Effect of language intervention on syntactic skill levels in preschoolers. Developmental Psychology, 42, 164-174. 